\title{
El extractivismo minero en América Latina: planteamientos, paralelismos y presunciones desde el caso de Guatemala
} The mining extractivism in Latin America: Expositions, parallels and presumptions from the case of Guatemala

\section{Manuel Ignacio Martínez Espinoza*}

Perfiles Latinoamericanos, 27(53) | 2019

DoI: $10.18504 / \mathrm{pl} 2753-001-2019$

Recibido: 11 de julio de 2016

Aceptado: 23 de julio de 2018

\section{Resumen}

El artículo estudia el extractivismo minero en América Latina esgrimiendo la tesis de que, a pesar de ser un fenómeno complejo, puede sistematizarse en pautas generales que configuran un patrón analítico en la región. A partir de la exposición de un caso significativo (la mina Marlin en Guatemala), se plantean cuatro paralelismos sobre el extractivismo minero en América Latina: el auge de la minería transnacional, el apoyo institucional, la apropiación territorial y la conflictividad emergente. Por último, se concluye que dichos paralelismos del extractivismo minero conducen a dos temas insoslayables en América Latina: el modelo primario-exportador y la democracia.

\begin{abstract}
This article studies mining extractivism in Latin America by developing an argument, which sustains that although a complex phenomenon, mining extractivism can be systemized in general standards. These standards can be again configured as an analytical pattern in the region. Building on a meaningful case study (the Marlin mine in Guatemala), the article outlines four parallelisms on mining extractivism in Latin America: the transnational mining at its peak, the institutional support, the territorial appropriation and the emerging unrest. Finally, the article suggests that these parallelisms of mining extractivism lead us to two unavoidable issues in Latin America: The primary exporting model, and democracy.
\end{abstract}

Palabras clave: extractivismo, minería, movimientos sociales, democracia, Guatemala, América Latina.

Keywords: Extractivism, mining, social movements, democracy, Guatemala, Latin America.

* Doctor en Procesos Políticos Contemporáneos por la Universidad de Salamanca, España. Catedrático Conacyt comisionado al Centro de Estudios Superiores de México y Centroamérica de la Universidad de Ciencias y Artes de Chiapas. Integrante del Observatorio de las Democracias: Sur de México y Centroamérica | manuel.martinez.espinoza@gmail.com 
Cada generación se cree predestinada para rehacer el mundo.

La mía sabe, sin embargo, que no lo rehará.

Pero quizás su tarea es mayor.

Consiste en impedir que el mundo se deshaga.

Albert Camus

\section{Introducción}

L

os análisis críticos contemporáneos sobre América Latina están incorporando cada vez más al extractivismo, en especial el minero, como una variable independiente de gran preponderancia. Actualmente, es común encontrar publicaciones sobre el particular que, desde diversos ámbitos y disciplinas, examinan generalidades de casos significativos en América Latina y/o dimensiones de su impacto (alteraciones ecológicas, conflictividad social, incidencia económica o tergiversación política). No obstante, aunque dicho estado del arte contiene obras comparativas críticas, sustentadas y profusas, ${ }^{1}$ se echa en falta estudios con un esquema analítico que plantee la articulación de las esferas convergentes en el extractivismo minero proyectando las reflexiones a escala regional. Esto es, textos que vinculen la multiplicidad de variables que confluyen en torno al fenómeno (económicas, políticas, sociales, jurídicas, ecológicas) para proponer un modelo explicativo comparativo e integral en América Latina.

Aunque el fenómeno es complejo por ser multifactorial, enrevesado y apremiante, en este artículo se postula que, al ser una expresión de condiciones estructurales mayores, el extractivismo minero puede sistematizarse en pautas discernibles que configuran un patrón analítico sobre ese nodo temático. Dicho de forma más puntual, que aun con las particularidades que asume en los casos nacionales, gracias a que el extractivismo minero es resultado de procesos estructurales, históricos y mundiales, ${ }^{2}$ analíticamente es factible configurar

1 Por ejemplo, Alimonda (2011), Almonte \& Sánchez (2016), Daumas (2013), Delgado (2010), Machado (2011), ocmal (2015), Seoane, Taddei \& Algranati (2013) y Svampa (2012).

2 Las condiciones originarias del extractivismo son sistematizadas por José Seoane, quien encuentra su génesis en cuatro procesos estructurales: 1) la particular forma de acumulación capitalista caracterizada por la apropiación privada y violenta de los bienes naturales; 2) las características del nuevo orden internacional forjado por la globalización neoliberal y la imposición de una nueva división internacional del trabajo; 3) la tercera revolución científico-tecnológica que abre las puertas para el despliegue de un profundo e inimaginado proceso de mercantilización (de control y explotación) de la naturaleza y la vida a escala global, y 4) la crisis contemporánea multidimensional caracterizada como civilizatoria (Seoane, 2013a: pp. 26-27). 
un modelo de ámbitos, actores, intereses, instituciones, procesos, impactos y corolarios del fenómeno en América Latina. Esta inferencia es el argumento central del presente texto.

Además, este análisis contribuye también a los estudios sobre el extractivismo minero en América Latina con tres aportes. En primer lugar, con el uso del método comparado a partir de un caso significativo, lo cual coadyuva a contrastar las inferencias planteadas. En segundo, con la conjunción de múltiples variables (ecológicas, sociales, políticas, económicas, jurídicas) que pretenden entablar un análisis interdisciplinario, integral y regional sobre el extractivismo minero. Y en tercero, con la sistematización del universo de estudios previos y la incorporación de datos actualizados.

Este artículo se despliega en tres apartados. En los "planteamientos", se presenta un breve marco general del extractivismo minero en América Latina y se expone uno de los casos más emblemáticos sobre el tema: el de la mina Marlin en Guatemala. Posteriormente, en los "paralelismos", se exponen cuatro analogías del caso guatemalteco con el resto de los latinoamericanos, mismas que son los basamentos del modelo analítico que se propone aquí. En la última sección, las "presunciones", se formulan unas reflexiones finales que sistematizan los patrones identificados y plantean núcleos centrales e insoslayables del extractivismo minero en América Latina.

\section{Planteamientos. El extractivismo minero en Guatemala}

Debido al aumento de la demanda de recursos básicos, provocada por crisis climáticas, energéticas y de biodiversidad (Mander, 2007), los conflictos por el acceso, control y usufructo de los recursos naturales se han incrementado en las últimas décadas en el mundo. ${ }^{3}$ De esta forma, la etapa actual del capitalismo se caracteriza por un proceso de acumulación por desposesión (Harvey, 2004) que tiene al modelo extractivo como uno de sus fundamentos constitutivos (Giarracca \& Teubal, 2010).

América Latina es un campo de batalla primordial en este esquema. Gracias a su riqueza biológica, ${ }^{4}$ se han expandido las actividades extractivas en la región, donde la minería figura como una de las más significativas. A su vez, los conflictos originados por tal motivo son numerosos, lo que ha suscitado múltiples

3 Como se destaca en un informe de Naciones Unidas, más del 40\% de los conflictos civiles en los últimos sesenta años han estado relacionados con los recursos naturales (UNEP, 2009).

4 Aunque América Latina y el Caribe constituyen solo el 16\% de la superficie terrestre, poseen el 40\% de la biodiversidad mundial (UNDP, 2010). 
movimientos de resistencia. Uno de los grupos poblacionales más afectados por el extractivismo son los pueblos indígenas, ${ }^{5}$ al punto que dicho agravio ha sido la causa principal de sus movilizaciones en la última década (CEPAL, 2014: p. 21), lo cual ha ocurrido casi simultáneamente al reconocimiento discursivo e institucional del marco jurídico-normativo internacional de derechos de los pueblos indígenas en América Latina. ${ }^{6}$

En consonancia con la situación continental, en Guatemala han aumentado las disputas por los territorios y los recursos naturales con los pueblos indígenas. De hecho, este ámbito ha sido la principal causa de la violación a sus derechos y, por lo tanto, el instigador de sus movilizaciones en los últimos años (ORACACNUDH, 2012: pp. 186-255). La minería ${ }^{7}$ ocupa un lugar preponderante en las contiendas vinculadas al extractivismo en Guatemala, e incluso es el punto de mira del repertorio de acción colectiva más simbólico de la última década en Centroamérica: las consultas comunitarias.

Siguiendo la tendencia de América Latina, las actividades mineras se expandieron en Guatemala a partir de la segunda mitad de la década de los noventa. Ello se confirma al apuntar que, de 1997 a 2011, el Ministerio de Energías y Minas de dicho país otorgó 398 licencias de exploración y explotación, cifra que multiplicó por tres la cantidad que hasta entonces se había dado. ${ }^{8}$ Para 2015, se habían concedido 342 licencias mineras y existían 552 en trámite (Bastos \& De León, 2015: p. 55).

Se puede afirmar que la conflictividad vinculada a la minería en Guatemala se detonó cuando se autorizó la licencia de explotación (sin consulta previa) por 25 años a la compañía Glamis Gold Ltd. (de capital canadiense), la cual, a través de su subsidiaria Montana Exploradora, se encargó de usufructuar de

5 La Comisión Económica para América Latina y el Caribe estima la población indígena en cerca de 45 millones, agrupados en 826 pueblos (CEPAL, 2014). De estos, entre el 70 y el $90 \%$ viven de las tierras con mayor diversidad biológica (wwF International \& Terralingua, 2000). Por ejemplo, habitan el $86 \%$ de las áreas boscosas protegidas de América Latina (BID, 2012).

$6 \mathrm{Al}$ no ser este el espacio para el análisis de los derechos de los pueblos indígenas y su impacto en América Latina, se sugiere revisar los textos de Martínez (2015) y Rodríguez-Piñero (2007).

7 En este texto, la minería se entiende como el conjunto de actividades referentes al descubrimiento y la extracción de minerales que se encuentran debajo de la superficie terrestre (Carrere, 2004: p. 15).

8 La licencia minera es el instrumento legal que respalda al titular en la ejecución de sus operaciones mineras. En Guatemala se identifican tres tipos: 1) De Reconocimiento: para identificar y localizar posibles áreas para exploración; 2) De Exploración: para localizar, estudiar, analizar y evaluar los yacimientos para los cuales haya sido otorgada; y 3) De Explotación: para explotar los yacimientos para los cuales haya sido otorgada. Esta última se da hasta por un plazo de 25 años, que puede prorrogarse hasta por un periodo idéntico (cfr. MEM, 2004). Aunque las licencias mineras que se extienden abarcan 20 de los 22 departamentos en los que se divide Guatemala, se concentran en Izabal, San Marcos, Huehuetenango y Alta Verapaz, de población mayoritariamente indígena. Véanse ORACACNUDH (2012: p. 210) y Yagenova (2012: pp. 13-14). 
octubre de 2005 a mediados de 2017 la mina Marlin, ubicada en el departamento de San Marcos.

La mina Marlin, que utilizó una combinación de tecnología mixta de tajo abierto y mina subterránea, ocupó $6.5 \mathrm{~km}^{2}$ en los límites de los municipios de San Miguel Ixtahuacán y Sipakapa, en las inmediaciones de los ríos Tzalá y Quivichil; el 85\% de la mina se encontraba en San Miguel Ixtahuacán y el $15 \%$ restante en Sipakapa (mapa 1). Esta área comprende los territorios tradicionales de los pueblos mam y sipakense.

Mapa 1. Ubicación del proyecto Mina Marlin

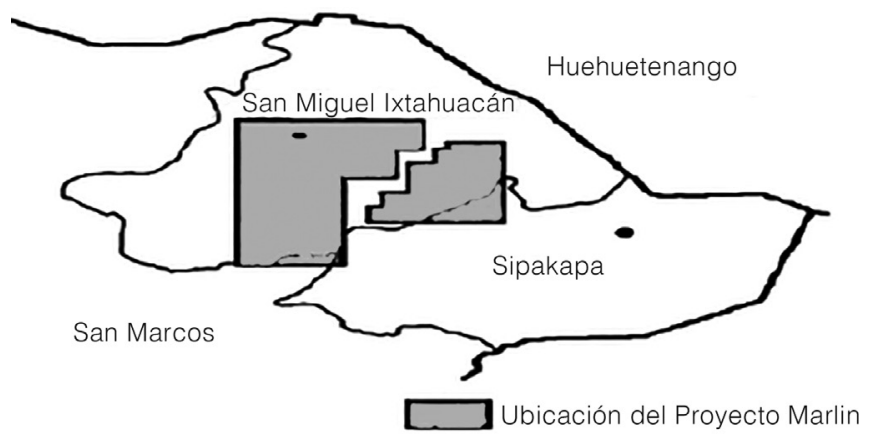

Fuente: Castagnino (2006: p. 6).

Montana Exploradora previó obtener ganancias por US\$753 millones. No obstante, tan solo entre 2006 y 2010, se benefició con US\$594.3 millones (Zarsky \& Stanley, 2011: p. 20). De tal cantidad, Guatemala ingresó a sus arcas US\$ 51.3 millones en impuestos y regalías; es decir, el 8.6\%. En realidad, la mina sobrepasó las expectativas, pues en 2003 se calculó que se producirían 200 mil onzas de oro en diez años, pero en 2015 llegó a un acumulado de 250 mil onzas. ${ }^{9}$

Desde el inicio de sus operaciones, el proyecto minero de Glamis Gold suscitó una polarización muy alta. Por el lado del posicionamiento a favor, encabezado por las autoridades gubernamentales (sobre todo centrales) y el sector privado, los argumentos se esbozaron vinculando la minería con el desarrollo y el crecimiento económico del país. La postura de Óscar Berger, en ese entonces

9 Véase http://www.prensalibre.com/economia/economia/mina-marlin-cerrara-produccion-en-mayo 
presidente de Guatemala, resulta reveladora pues para él la minería representaba "una oportunidad para que el país avanzara".

A su vez, los opositores, constituidos por comunidades indígenas y organizaciones de diversa índole (civiles, ecologistas, religiosas), justificaron su postura señalando los impactos ambientales, los escasos beneficios económicos y la exclusión de los pobladores en los procesos decisorios sobre el proyecto y el territorio. ${ }^{10}$

La falta de mecanismos institucionales para dirimir tales posturas, fuera de un esquema de suma cero, ${ }^{11}$ contribuyó a que el clima se fuese enardeciendo y emergieran enfrentamientos violentos, donde incluso se perdieron vidas humanas.

Pero más allá de la virulencia de las disputas, el caso de San Marcos resulta enriquecedor en términos analíticos porque propició la puesta en práctica del derecho a la consulta por las propias comunidades afectadas. Efectivamente, ante la falta de información y la imposición de las actividades mineras, los opositores a dichas actividades extractivas enmarcaron sus movilizaciones en la gramática de los derechos colectivos, de manera que las comunidades y organizaciones comenzaron a reivindicar sus derechos al territorio, a definir su propio desarrollo y, especialmente, a ser consultadas según los ordenamientos internacionales.

Indudablemente, la consulta realizada en Sipakapa en 2005 es la más simbólica por el contexto de su realización y por su alcance. La población de Sipakapa, con acuerdo del Consejo Municipal, convocó a una consulta sobre la minería para el 18 de junio de 2005. La consulta fue preparada mediante la articulación de organizaciones locales, nacionales e internacionales, entre ellas, el Consejo de Desarrollo Municipal, el juez de paz local, MadreSelva, la Asociación Nacional de Abogados Mayas, la Iglesia Católica de San Marcos y la Defensoría Indígena de Derechos Humanos, entre otros (Walter \& Urkidi, 2015: p. 349).

Montana Exploradora interpuso dos amparos y distribuyó volantes donde se afirmaba que la consulta no se realizaría. No obstante, el procurador de Derechos Humanos consiguió que la Corte de Constitucionalidad revocara ambos recursos jurídicos. Tal como estaba planeado, la consulta se llevó a cabo en trece comunidades del municipio de Sipakapa; de estas, once votaron contra la minería, una se abstuvo y la restante votó a favor con solo tres votos de diferencia.

10 Los posicionamientos en contra de la mina Marlín se han sustentado en argumentos que van desde lo medioambiental hasta lo cultural, pasando por lo jurídico, económico y político. Los detalles pueden consultarse en Castagnino (2006), OCGCI (2010) y Yagenova (2012).

11 En la teoría de juegos, un juego de suma cero es aquel donde las ganancias de cualquier actor solo pueden producirse a costa del total de pérdidas idénticas en el balance conjunto del resto de actores. 
Posteriormente, los organizadores se movilizaron para promover los resultados de la consulta. Dado que las respuestas de los poderes públicos no satisficieron a los demandantes, estos llevaron el caso ante la Comisión Interamericana de Derechos Humanos (CIDH), la cual otorgó medidas cautelares a dieciocho comunidades indígenas afectadas en 2010. ${ }^{12}$ En su resolución, la CIDH argumentó que esas medidas estaban destinadas a garantizar la vida e integridad de las comunidades indígenas, razón por la que solicitó al gobierno de Guatemala, entre otros requerimientos, suspender los trabajos de la mina, descontaminar las fuentes de agua de las comunidades, atender los problemas de salud e implementar sistemas de protección con la participación de los beneficiarios. Siete años después, y a pesar de los acercamientos entre las partes, las medidas cautelares de la CIDH aún no se han implementado plenamente.

No obstante, el proyecto extractivo en San Marcos tomó un viraje importante pues, aunque el 9 de diciembre de 2011 la CIDH modificó las medidas cautelares para suprimir la solicitud de suspensión de operaciones de la mina y de que podría haber seguido una década más con la explosión de la cantera, se anunció que a mediados de 2017 comenzaría el cierre de sus operaciones en gran parte por el desgaste que les produjo "la oposición manejada por algunas oenegés antimineras". ${ }^{13}$

El caso de la mina Marlin es relevante porque fue ampliamente seguido nacional e internacionalmente, además de que tuvo resonancia en otras partes del país con la réplica de la estrategia de las consultas comunitarias contra la minería. ${ }^{14}$ Pero, sobre todo, trasluce tendencias que se han registrado con otros proyectos mineros en el país. Por principio de cuentas, se puede caracterizar un bloque introductorio, donde gracias al apoyo legal, tributario y hasta discursivo del Estado - fundamentalmente del gobierno central — se promueve el arribo de capital y empresas transnacionales en el sector minero. Entonces,

12 Medida cautelar número MC-260-07. Según lo establece su Reglamento, en situaciones de gravedad y urgencia la CIDH podrá solicitar que un Estado adopte medidas cautelares para prevenir daños irreparables a las personas o al objeto del proceso en conexión con una petición o caso pendiente, así como a personas que se encuentren bajo su jurisdicción. Véase http://www.cidh.oas.org/medidas/2010.sp.htm Véase https://elperiodico.com.gt/inversion/2017/08/21/mineria-redujo-su-aporte-al-pib-en-1-93 -por-ciento-en-ultimos-anos/

14 Las primeras consultas en Guatemala sobre las actividades extractivas en el altiplano indígena iniciaron el 18 de mayo de 2005 en Comitancillo (departamento de San Marcos). Desde esa fecha y hasta 2015, se han contabilizado 94 "consultas comunitarias de buena fe", realizadas en 74 municipios de doce departamentos del país, siendo los de mayor convocatoria Totonicapán, Huehuetenango, San Marcos y Santa Rosa; es decir, la franja indígena del occidente y noroccidente del país. El $88.59 \%$ de las consultas se ha enfocado en el tema de la minería (Recuperado el 20 de agosto de 2018, de http:/www.gt.undp.org/ content/guatemala/es/home/ourperspective/ourperspectivearticles/2017/01/24/las-consultas-comunitarias-mecanismos-de-agencia-colectiva-en-las-luchas-por-el-bienestar-.html). Para profundizar en el tema, véanse Anaya (2011), cSA et al. (2010), Walter \& Urkidi (2015) y Yagenova (2012). 
sin consulta previa a lo población residente, o con acercamientos meramente informativos, arbitrarios y sesgados (Yagenova, 2012), se conceden las licencias y se instalan las minas a cielo abierto con tecnología intensiva.

Una segunda etapa inicia cuando la población se entera de la existencia del proyecto extractivo al observar camiones, maquinaria pesada o simplemente las vallas que delimitan el perímetro de la mina. Comienza así un periodo en el que las comunidades y las organizaciones muestran su desacuerdo por el arribo de la megaminería sin su consentimiento y sus preocupaciones por los peligros que ella implica para su territorio. Como respuesta, se activa una conjura de la oposición con promesas de empleos, infraestructura y desarrollo, por parte de la empresa minera y del gobierno central.

Una tercera fase sobreviene cuando, pasado cierto tiempo, el empleo y la infraestructura resultan escasos para todos los habitantes o lucen insuficientes ante los diversos impactos medioambientales del proyecto minero. Estallan entonces movilizaciones y actos de protesta social más intensos que reclaman la suspensión de las minas. La polarización se profundiza porque en los espacios afines a la minería se estigmatiza a los opositores, se invoca el Estado de derecho y, finalmente, surgen las amenazas, acosos, encarcelamientos y la represión física contra los opositores.

Por último, los acontecimientos pueden seguir varios cursos. Puede que intervenga el Poder Judicial o instancias de derechos humanos nacionales e internacionales con resultados inciertos. Puede que se liberen a los acusados aunque con voluminosos expedientes judiciales sobre sus espaldas. De cualquier forma, y a pesar de la conflictividad, el proyecto minero tiene altas probabilidades de mantenerse una vez concesionado gracias al amparo institucional, aunque teniendo como desafío vital para su subsistencia las impugnaciones de los movimientos sociales.

\section{Paralelismos. El extractivismo minero en América Latina}

Como ha quedado expuesto en el apartado anterior, en el extractivismo minero en Guatemala convergen múltiples variables que denotan al menos cuatro procesos imbricados: la irrupción de la minería transnacional, los apoyos institucionales para dicho auge, las afectaciones territoriales y la irrupción de movimientos socioambientales que interpelan al extractivismo minero. Como se explicará en este apartado, tales generalidades del caso guatemalteco son factibles de extrapolarse al resto de los países latinoamericanos. Se trata de cuatro paralelismos advertidos sobre el extractivismo minero en América Latina. 
La primer analogía del fenómeno en América Latina es una tendencia iniciada hace dos décadas: el incremento de la minería espoleado por el capital transnacional.

La génesis de este extractivismo minero contemporáneo ${ }^{15}$ podemos situarla en el incremento de los precios internacionales de las materias primas y los bienes de consumo, demandados por los países centrales y las potencias emergentes a inicios del 2000 (Svampa, 2012), lo que provocó que los metales y los minerales se reconfiguraran en activos financieros que conforman una esfera de inversión, lo que se ha catalogado como commodities. ${ }^{16}$

Efectivamente, dadas sus profusas vetas minerales, ${ }^{17}$ desde la década de 1990 América Latina se ha convertido en el destino principal de la inversión minera mundial, de la que cerca del $82 \%$ se concentra en cinco países: Perú, Chile, Brasil, México y Colombia (Campodónico \& Ortiz, 2002).

Otro indicador ilustrativo del auge de la megaminería en América Latina son las concesiones, esto es, las autorizaciones y los derechos que los gobiernos conceden para la exploración y/o explotación de minerales y metales en sus territorios.

15 Cuatro breves acotaciones sobre este concepto: $i)$ se trata de "un tipo de extracción de recursos naturales, en gran volumen o alta intensidad, y que están orientados esencialmente a ser exportados como materias primas sin procesar, o con un procesamiento mínimo" (Gudynas, 2013a: p. 3); ii) al remitir a las actividades que utilizan o explotan bienes que son considerados no renovables (Seoane, 2013a: p. 24), el extractivismo "no contempla solamente actividades típicamente consideradas como tal (minería e hidrocarburos), sino también los agronegocios o la producción de biocombustibles" (Svampa, 2012: p. 17) e incluso actividades pesqueras y madereras (Seoane, 2013a: p. 24); iii) aunque algunos autores prefieren utilizar el término "neoextractivismo" para subrayar su intensidad contemporánea, en este texto se ha elegido usar "extractivismo" para resaltar el carácter histórico-estructural que se mantiene en la región, y iv) hay autores que ven similitudes entre el concepto de extractivismo y el de acumulación originaria de Karl Marx: "Con todo, si seguimos el análisis que Marx (1975 [1894]) ofrece sobre la acumulación originaria de capital — la cual pondera el florecimiento de las manufacturas laneras y la consiguiente alza de precios como acicate para los abusos y el despojo- - encontraremos que la situación descrita por el autor es muy similar al actual neoextractivismo" (Villafuerte, 2014: p. 123).

16 "Se refiere a bienes que son considerados homogéneos independientemente de su origen, donde no existe una fuerte diferenciación entre sus variedades, que incluso pueden estar estandarizados, y que son comercializados en grandes volúmenes. Una materia prima es abordada por el mercado como un commodity entendiendo que tiene atributos similares en los distintos sitios de obtención. Por ejemplo, una tonelada de cobre de Chile sería similar a una obtenida en Perú, y los mercados otorgan indicaciones de demandas o precios sobre el cobre en general, y no sobre sus variedades en particular" (Gudynas, 2013a: p. 6).

17 "América Latina cuenta con inmensos activos de recursos naturales no renovables: posee un 13\% de las reservas de petróleo del planeta, $65 \%$ del litio, $49 \%$ de la plata, $44 \%$ del cobre, 33\% del estaño, 32\% del molibdeno, $26 \%$ de la bauxita, $23 \%$ del níquel, $22 \%$ del hierro y $22 \%$ del zinc. Según las tendencias de la década 2000-2010, 13 países de la región están entre los 15 mayores productores de materias primas minerales del mundo" (RRI, 2013: p. 40). 
Así, a partir del año 2000 se verifica un incremento en el número de concesiones mineras en los países latinoamericanos. Por ejemplo, en Brasil pasaron de 142 en 1999 a 404 en 2009, es decir, casi 300\% más en diez años (MmE, 2011: p. 25). En Guatemala había 27 licencias mineras en el año 2000, para enero de 2012 ya eran 116 (Villafuerte, 2014: pp. 113-114); es decir, en poco más de once años se incrementaron en 430\%. En Perú el número de concesiones mineras se multiplicó por ocho entre 1992 y 2014 (Baca \& Ávila, 2015: p. 14).

Este ascenso en el número de las concesiones mineras ha conllevado un aumento en su extensión territorial. Como puede constatarse en el cuadro 1, las últimas cifras oficiales recopiladas revelan una cuantiosa cantidad de hectáreas concesionadas a la minería en América Latina, lo que implica un porcentaje importante de la superficie total de cada país. Por ejemplo, Chile tiene concesionado $21 \%$ de su territorio con la minería, Perú más del $14 \%$ y México más del $11 \%$. Otros casos presentan porcentajes menores al $10 \%$ de su territorio pero que superan el millón de hectáreas, como Bolivia que ha concesionado más de dos millones de hectáreas; Colombia, con más de cinco millones de hectáreas; Argentina, con dieciocho millones de hectáreas que representan el $6.5 \%$ de su territorio, y Nicaragua con más de un millón de hectáreas.

Cuadro 1. Territorio concesionado para actividades mineras en América Latina

\begin{tabular}{lccc}
\hline País & $\begin{array}{c}\text { Total de hectáreas } \\
\text { concesionadas a la minería }\end{array}$ & $\begin{array}{c}\text { Porcentaje del territorio nacional } \\
\text { concesionado a la minería }\end{array}$ & Fecha del dato \\
\hline Argentina & $18300000^{1}$ & 6.5548 & 2016 \\
Bolivia & $2285583^{2}$ & 2.08 & 2013 \\
Chile & $15752999^{3}$ & 21 & 2017 \\
Colombia & $5292165.80^{4}$ & 4.6351 & 2012 \\
Ecuador & $772728.93^{5}$ & 2.87 & 2016 \\
Guatemala & $527983.63^{6}$ & 4.8488 & 2017 \\
Honduras & $184754.445^{7}$ & 1.6423 & 2017 \\
México & $22100000^{8}$ & 11.3 & 2017 \\
Nicaragua & $1194909.23^{9}$ & 9.1651 & 2017 \\
Panamá & $227556.307^{10}$ & 2.9521 & 2016 \\
Perú & $18854318.62^{11}$ & 14.6701 & 2017
\end{tabular}

Fuente: Elaboración propia con base en ${ }^{1}$ Ministerio de Energía y Minería de Argentina (2016); ${ }^{2}$ Servicio Geológico Minero. Estado Plurinacional de Bolivia (2013); ${ }^{3}$ Ministerio de Minería. Gobierno de Chile ( 2018); ${ }^{4}$ Ministerio de Energía y Minas (2014); ${ }^{5}$ Agencia de Regulación y Control Minero. Rendición de cuentas 2016 ( 2016); ${ }^{6}$ Ministerio de Energía y Minas. Gobierno de la República de Guatemala (s. f.); ${ }^{7}$ Instituto Hondureño de Geología y Minas ( 2017); ${ }^{8}$ Gobierno de los Estados Unidos Mexicanos. Presidencia de la República (2017); ${ }^{9}$ Ministerio de Energía y Minas. Dirección General de Minas. Dirección de administración y control de concesiones (2017); ${ }^{10}$ Ministerio de Comercio e Industrias. Gobierno de la República de Panamá (2016a, 2016b); ${ }^{11}$ Ministerio de Energía y Minas. Instituto Geológico, Minero y Metalúrgico (2017)

El incremento de las concesiones mineras, que confirma el auge de la minería transnacional en América Latina, devela el factor que lo ha propiciado: 
el soporte institucional, el cual también es una pauta del extractivismo en la región.

Segundo paralelismo: el apoyo institucional

En América Latina se ha registrado un patrón de facilidades institucionales que concuerda con el incremento del extractivismo en los últimos ańos. Tales aquiescencias involucran los ámbitos normativos, administrativos, tributarios y hasta discursivos.

En el ámbito normativo, desde la década de 1990 los países de la región han edificado nuevas legislaciones mineras o han reformado las existentes. Argentina (1993 y 1995), Brasil (1996 y 2015), Bolivia (1997 y 2014), Colombia (2014), Costa Rica (1998), Cuba (1995), Ecuador (1991 y 2008), El Salvador (2012), Guatemala (1997), Honduras (1998 y 2013), México (2014), Panamá (2011), Perú (1991), Uruguay (1991 y 2011) y Venezuela (1999 y 2010) fueron los países donde se modificó el marco jurídico acerca de la minería para ofrecer a las empresas transnacionales "seguridad jurídica, garantía a la inversión y un clima de negocios atractivo" (RRI, 2013: p. 41); esto es, para institucionalizar la minería transnacional. ${ }^{18}$ Los casos de Brasil, Bolivia, Ecuador, Honduras, Uruguay y Venezuela son llamativos puesto que reformaron su marco normativo minero en dos décadas diferentes.

A grandes rasgos, las reformas a las legislaciones han promovido facilidades para las empresas mineras que pueden agruparse en las simplificaciones administrativas y las ventajas tributarias. Por un lado, las directrices reglamentarias se han orientado a allanar el procedimiento de adjudicación de las concesiones mineras, lo que, entre otros cambios, ha implicado reducir los plazos, requisitos y contenidos de los estudios de impacto ambiental que las empresas están obligadas a realizar. Por ejemplo, en Bolivia se redujeron los plazos para la obtención de la Declaratoria de Impacto Ambiental de 190 a 35 días. En Colombia, el Decreto de 2014, conocido como de "licencias exprés", le restó treinta días a la autoridad para decidir sobre la autorización de licencias ambientales; pero lo destacado es que el gobierno primero adjudica la concesión minera y luego otorga la licencia ambiental. En Chile, Guatemala y Perú los estudios

18 Sin ser exactamente una elaboración o reforma legislativa, conviene apuntar la firma en 2017 del Nuevo Acuerdo Federal Minero entre el gobierno nacional de Argentina y las llamadas "provincias mineras". Tal convenio es un ejemplo de las vías normativas que los Poderes Ejecutivos latinoamericanos suelen diseñar para allanar institucionalmente al extractivismo minero omitiendo la intervención de otros poderes, como el Legislativo. 
de impacto ambiental son posteriores al permiso de las concesiones mineras (OCMAL, 2012: p. 124).

Las ventajas tributarias se refieren a los incentivos fiscales que se dan a las inversiones para acelerar la amortización de los activos y la obtención de las tasas de ganancia de las empresas. Se trata de atajos o reducciones para el pago de impuestos y regalías. Por ejemplo, en Guatemala las regalías que las empresas pagan al Estado no superan el 5\% sobre el valor bruto del mineral producido. En Argentina, Brasil y Nicaragua las regalías no superan el 3\%. En El Salvador, la reforma de 2012 redujo las regalías del 4 al 2\%. En México, las empresas mineras pagaron el $1 \%$ de derechos en relación con su producción en 2014, cantidad que, aun siendo baja, es superior al $0.4 \%$ que dichas empresas pagaron al país en $2006 .{ }^{19}$

El apoyo institucional a las inversiones mineras también se ha sustentado en dispositivos discursivos que, entroncándose en una matriz ideológica hegemónica sobre el desarrollo, esgrimidos por figuras públicas y utilizando la influencia de los medios de comunicación, se han puesto al servicio del extractivismo.

La minería transnacional ha articulado sus argumentos con el discurso del desarrollo para autolegitimarse (Leff, 2003). En consecuencia, se han producido maniobras retóricas en cada país latinoamericano para amalgamar la minería con campos semánticos como "progreso", "crecimiento" y hasta "sostenibilidad". Se construyen así ideas fuerza que afianzan la retórica legitimadora para favorecer la minería (Antonelli, 2009: p. 42). De este modo, el extractivismo minero ha sido respaldado institucionalmente en América Latina mediante narrativas de pretensión hegemónica que buscan legitimarlo. Mirta Antonelli lo bosqueja magistralmente:

como toda colonización, la minería transnacional requiere no sólo la legalidad de las normativas que institucionalizaron el estado de derecho y la seguridad jurídica en los 90 conforme a las pretensiones empresariales y de inversionistas sino una lengua, una episteme, una genealogía, iconografías y retóricas, su ética y su filantropía, sus afectos públicos y pasiones políticamente fuertes, y una profusión de discursos e instituciones de legitimación, incluido el arte. (Antonelli, 2009: pp. 100-101).

Todos los anteriores son procesos institucionales para asegurar las condiciones sociopolíticas de reproducción del extractivismo minero que de manera acertada han sido catalogadas como "estrategias de gobernabilidad del modelo

19 Los datos provienen de http://www.idconline.com.mx/juridico/2014/01/21/mineria-mas-gravada-que -nunca para Argentina y Brasil; de OCMAL (2011) para El Salvador; de RRI (2013) para Colombia y Guatemala; de Garay (2014) para Nicaragua, y de Saúl (2015) para México. 
extractivo exportador" (Seoane, 2013b). Se trata, como arriba se puntualizó, de un conglomerado de métodos, técnicas y términos que pretenden asegurar la exitosa aplicación del extractivismo, en este caso, minero. ${ }^{20}$

El amparo institucional en los ámbitos normativo, administrativo, tributario y discursivo ha influido en el apogeo de la minería transnacional en América Latina. Con todo, ese auge es apenas un primer acercamiento que permite asomarse y al mismo tiempo reclama un mayor escrutinio sobre la ocupación minera de los territorios, lo que, al replicarse en la región, se transforma en una pauta de ese sector extractivo.

\section{Tercer paralelismo: la apropiación territorial}

A la megaminería no le basta con asentarse en el lugar del yacimiento: precisa del control de prácticamente todo el territorio. Esto se explica por los métodos contemporáneos para la extracción extensiva de los metales y los minerales.

Actualmente se utiliza con mayor preponderancia la minería de superficie debido a que incorpora tecnologías que permiten la explotación intensiva de minerales. ${ }^{21}$ Por ejemplo, se ha estimado que con el método "a cielo abierto" se produce tres veces más carga mineral al día que con el método subterráneo (Sariego et al., 1988: p. 321).

Básicamente, la minería a cielo abierto consiste en la voladura de material rocoso, que posteriormente se tritura, se baña en una mezcla de agua con cianuro y otros ácidos (la lixiviación) y se concluye con la fundición de los metales. ${ }^{22}$ Con este método se destruyen enormes extensiones de superficie montañosa, se usan grandes cantidades de explosivos y sustancias tóxicas, y se gasta intensivamente el agua (Machado, 2011: p. 165).

Efectivamente, la minería a cielo abierto requiere de cantidades exorbitantes de agua para llevar a cabo sus operaciones, pues se calcula que, desde la puesta en marcha hasta su cierre, una mina requiere de al menos un metro cúbico de agua por segundo de forma ininterrumpida (Machado, 2010: p. 78). Pero

20 Además de los apoyos institucionales ya enunciados, vale destacar otras técnicas y terminologías que integran de forma relevante las estrategias de gobernabilidad del extractivismo, como la falsa dicotomía entre la cuestión social y la ambiental, la gobernanza como un término que asigna funciones de gobierno a las propias mineras, la responsabilidad social y ambiental de las empresas, así como los diversos procedimientos para establecer un campo de saberes autorizados afín al extractivismo que se ha denominado "neutralización de los expertos". Para conocer un análisis integral de estas estrategias, véase Seoane (2013b).

21 Más del 60\% de los minerales extraídos actualmente en el mundo se obtienen con la minería de superficie (Carrere, 2004: p. 16).

22 Para conocer a detalle el proceso de la minería a cielo abierto, revísese Morán (2013: pp. 3-6). 
las dosis pueden ser aún mayores. Por ejemplo, la mina Marlin de Guatemala utiliza 250 mil de litros de agua por hora (Castagnino, 2006: p. 13); la mina Veladero, en Argentina, gasta 396 mil litros de agua por hora y la mina Pascua Lama, dispuesta en los límites entre Chile y Argentina, consume 1296000 litros de agua por hora (Morán, 2013: p. 17). Para dar una idea de este consumo, se puede señalar que la cantidad por hora que gasta la mina Marlin equivale a la misma porción que consume una familia campesina durante veintidós años (Castagnino, 2006: p. 13). No es excesivo afirmar que las minas a cielo abierto tienden a acabar con los recursos hídricos por más grandes que estos sean (Hernández, 2014: p. 62).

Como puede intuirse, los efectos de la megaminería al medio ambiente son sumamente perjudiciales, pues a lo largo de sus procesos se liberan cantidades masivas de sustancias químicas, combustibles y explosivos (Morán, 2013: p. 7).

En primer lugar, cuando no la consume en su totalidad, la minería a cielo abierto contamina el agua de los territorios ya que, para separar los metales de la roca, emplea elementos y metales pesados como arsénico, azufre, cianuro, cobre, mercurio, plomo y uranio, los cuales contaminan las fuentes acuíferas y son altamente tóxicos para todo tipo de vida: "Los drenajes ácidos pueden 'eliminar' en esencia toda la vida acuática a lo largo de kilómetros de cursos cercanos y volver inaceptables las aguas subterráneas para muchos otros usos" (Morán, 2013: p. 7). Por aportar un dato, en 2013 la Dirección General de Aguas de Chile reconoció como zonas de catástrofe a ocho comunas donde existe actividad minera a gran escala (ocmal, 2015: p. 42).

En relación con el suelo, este es removido y deteriorado por los derrames y vertidos de materiales tóxicos y la sedimentación de polvo contaminado, perdiendo así sus funciones básicas. De igual forma, la megaminería es factor de polución para el aire, pues este "se deteriora por el incremento de emisiones de material particulado, metales pesados, vapores y gases (por ejemplo, óxidos de carbono, nitrógeno y azufre), y por los niveles de ruido" (RRI, 2013: p. 61).

La megaminería, por otra parte, impacta en las especies nativas del territorio debido a la alteración y pérdida de hábitat por la remoción de la cobertura vegetal, el relleno o desvío de cuerpos de agua, el incremento del ruido y la liberación de contaminantes en el ambiente, lo que obliga al desplazamiento y hasta la desaparición de especies vulnerables (RRI, 2013: p. 62).

Tales impactos hacen lógico suponer que la megaminería perjudica gravemente a las sociedades locales. Por principio de cuentas, la salud de los habitantes se ve seriamente afectada, pues enfermedades respiratorias, gastrointestinales, dermatológicas, endocrinas, cardiovasculares y neurológicas suelen presentarse por la exposición a los elementos que las minas dispersan en el medio ambiente (González, 2015). Asimismo, se suscita la desposesión de los recursos hídricos 
y otros bienes naturales que, hasta antes de la entrada de una mina, se habían destinado a los pobladores. Además, la contaminación, la degradación y la expropiación de los recursos naturales impactan negativamente en la producción y calidad de los alimentos obtenidos por vía agraria, ganadera, marina o forestal, lo que vulnera la soberanía alimentaria de las comunidades locales.

Una estrategia central para incrementar la productividad minera es la reorientación de las dinámicas locales al servicio de la mina. Por consiguiente, las empresas mineras, muchas veces con apoyo de los gobiernos, emprenden acciones para respaldar tal objetivo, sin importar su legitimidad o legalidad. La adquisición malversada de terrenos, el surgimiento de grupos armados paraestatales, la aparición del microtráfico y la prostitución, la pérdida de formas tradicionales de subsistencia, así como el desplazamiento forzado de poblaciones, son afectaciones constantes en las localidades donde se ha asentado un proyecto minero a gran escala (RRI, 2013: p. 12).

El extractivismo minero opera destruyendo la configuración local de los territorios, desarticulando los flujos socioproductivos endolocales y rearticulándolos como fragmentos subordinados a procesos productivos de alcance global. Considerando a los territorios como "socialmente vaciables" (Sack, 1986) o "sacrificables" (Svampa, 2012), se les uniforma para crear nuevos enclaves de exportación (Svampa, 2008: p. 19).

No puede haber megaminería sin el control de grandes extensiones de suelo, bosques, cimas, agua y biodiversidad. Por ello, los gobiernos conceden a las industrias extractivas la potestad de usufructuar el territorio bajo la nomenclatura de "declaratoria de utilidad pública" (Sánchez-Albavera \& Lardé, 2006). Las empresas mineras, cuando no tienen el monopolio, sí cuentan con la preponderancia para el acceso y la explotación de los bienes naturales, lo que se profundiza con el tiempo, pues las concesiones mineras en una región suelen tener una vigencia que oscila entre los 25 y los 30 años (RRI, 2013: p. 41).

Conviene subrayarlo: la minería transnacional demanda el control integral del territorio donde se asienta para cumplir con sus objetivos extractivos. Las afectaciones de las minas a los espacios, recursos y sociedades locales, evidenciadas en los países latinoamericanos durante los últimos años, ${ }^{23}$ atestiguan dicho proceso. No obstante, casi como regla politológica, a cada intento de dominación suele contraponerse al menos una acción de oposición. Tales resistencias, así como

23 Hay innumerables fuentes sobre los impactos ambientales y sociales de las minas por cada país latinoamericano. De tono más general y visión más continental, se recomiendan Carrere (2004), Delgado (2013), Giraud (2006), González (2015), Hernández (2014: pp. 60-64), Lillo (2015), Morán (2013), Nolasco (2011), OCMAL (2015) y RRI (2013). 
las reacciones de los Estados, serán la última de las pautas que se expondrán en relación a América Latina y los proyectos extractivos mineros.

Cuarto paralelismo: la conflictividad emergente

La megaminería ha generado una plétora de estragos que ha convertido el territorio en el espacio concreto donde el conflicto surge determinando los integrantes de las contiendas, los recursos en disputa y el catálogo de prácticas en pugna.

Efectivamente, a partir de finales de la década de 1990, justo en el mismo periodo del incremento de la megaminería, se observó el aumento de los conflictos vinculados con la minería en América Latina. Por ejemplo, el Atlas of Environmental Justice (EJOLT) registra una ampliación de los conflictos mineros a partir de 1997.

En los datos disponibles a mayo de 2016, el EJoLT contabiliza alrededor de 218 conflictos vinculados a la minería en Mesoamérica y Sudamérica. Por su parte, el Observatorio de Conflictos Mineros de América Latina (OCMAL) reconoce 210 conflictos que afectan a 335 comunidades de la región. ${ }^{24}$ Tales datos regionales coinciden con las cifras nacionales. Por ejemplo, del total de los conflictos registrados en Chile en mayo de 2016, el 77\% de ellos correspondían a los sectores de energía y minería (91 de 118). ${ }^{25}$ Del mismo modo, el 66\% de los conflictos socioambientales en Perú en julio del 2015 se relacionaban con la minería (91 de 138). ${ }^{26}$ Hay una correlación muy alta entre concesiones mineras y conflictos, como en Guatemala, donde 78 de los 101 municipios con licencias mineras (el 77\%) presenta algún conflicto (ICEFI, 2014: p. 30). Es factible afirmar que el extractivismo minero instiga la proliferación de los conflictos.

Aunque estos conflictos han sido catalogados como socioambientales (Svampa, 2012), ecológico distributivos (Martinez-Alier \& O'Connor, 1996) o de justicia ambiental (Urkidi \& Walter, 2011), se coincide en argumentar que se originan en las desigualdades en el acceso, control y distribución del territorio y sus recursos.

En cuanto a la composición, articulación y dinámicas de los movimientos sociales que irrumpen en el seno de estos conflictos, si bien el sustrato indígena

24 Véanse los mapas de ejolt y ocmaL en http://ejatlas.org/y http://mapa.conflictosmineros.net/ocmal_ $\mathrm{db} /$, respectivamente.

25 Consúltese el mapa en http://mapaconflictos.indh.cl/

26 Defensoria del Pueblo. Radiografia de conflictos sociales. Recuperado de http://www.defensoria.gob.pe/ blog/defensoria-del-pueblo-registro-209-conflictos-sociales-en-julio/ 
está presente de forma copiosa, ${ }^{27}$ es factible caracterizar su integración como plural, a su ensamblaje como multiescalar y a sus repertorios de acción colectiva como multicondensados.

Estos movimientos se constituyen con variados integrantes en ámbitos rurales y urbanos, sin distingo de género o edad: indígenas, campesinas y campesinos, sacerdotes, estudiantes, maestros y maestras, organizaciones de diversa índole (ambientales, productivas, religiosas, de cooperación al desarrollo) y hasta de gobiernos locales (en el caso de las consultas comunitarias). Esa pluralidad permite que estos movimientos se desplacen en distintas escalas, pues si bien surgen por un problema concreto local, en general se articulan a organizaciones $\mathrm{y}$ redes nacionales, regionales e internacionales. ${ }^{28}$

En relación con sus narrativas, lo que en la literatura especializada se conoce como "marcos cognitivos", ${ }^{29}$ ha ocurrido un proceso de enmarcamiento discursivo alrededor de nociones relacionadas con el medio ambiente, lo que Leff (2003) denomina "la ambientalización de las luchas indígenas y campesinas", esto es, "la emergencia de un lenguaje común que da cuenta del cruce innovador entre la matriz indígena comunitaria, la defensa del territorio y el discurso ambientalista" (Svampa, 2012: p. 22).

Respecto al repertorio de acción colectiva, el catálogo de prácticas de protesta de los movimientos socioambientales en América Latina ha sido misceláneo y multicondensado, oscilando entre los tipos de acción colectiva convencional, la alteración del orden y las confrontaciones directas (Tarrow, 2004: pp. 135153). Las prácticas han sido, entre otras, foros, asambleas, desplegados, marchas, bloqueos carreteros, clausuras simbólicas de minas, plantones, grafitis, pintas, escenificaciones dramáticas, huelgas de hambre, declaratorias de territorios libres de minería (Argentina, El Salvador, Guatemala, Honduras, México, Uruguay), consultas comunitarias (Argentina, Colombia, Ecuador, Guatemala, Perú), así como acciones más entroncadas en el ámbito institucional, como audiencias públicas y referendos (Argentina, Perú, Uruguay), o controversias jurídicas y propuesta de leyes.

Por su parte, la respuesta de los sectores favorables a la minería, en especial de los gobiernos centrales, suele caracterizarse por desacreditar y contraatacar a

27 Los pueblos indígenas están presentes en alrededor del 50\% de los conflictos ambientales registrados hasta la fecha en Latinoamérica según la base de datos del ejoLt (Martinez-Alier \& Walter, 2015: p. 90). Para conocer un listado reciente de este tipo de colectivos y redes nacionales e internacionales, véase $D i$ rectorio... O aliados contra el modelo extractivo minero, elaborado por Otros Mundos Chiapas, en http:// otrosmundoschiapas.org/materiales/docs/pdf/manuales/mineria/mineria_cap12_directorio.pdf

29 En la teoría de movilización de recursos, los marcos cognitivos (frame analysis) consideran que los movimientos definen estratégica y conscientemente una situación a través de procesos enmarcadores para facilitar la acción colectiva. 
los movimientos socioambientales asociando sus discursos y acciones al campo delictivo, esto es, criminalizando la protesta social, lo cual funciona como "un mecanismo de control social para neutralizar o inhibir cualquier conductamanifestación que pueda poner en riesgo o que cuestione las expresiones de poder imperantes y el modelo de desarrollo definido desde el Estado" (OCMAL, 2011: pp. 90-91).

Dicho tipo de disuasión ocurre en diferentes ámbitos interrelacionados: el discursivo, el judicial, el administrativo, y en la militarización y la acción policial (OCMAL, 2011). ${ }^{30}$ La criminalización de la protesta social inicia con la descalificación de los movimientos sociales. El aspecto crítico es que los estereotipos hacia quienes disienten del modelo extractivista minero no se quedan solo en agravios verbales sino que comportan un correlato jurídico. Así, los estigmas de delincuentes, saboteadores o terroristas conllevan su correspondencia legal, lo que se ha utilizado para confrontar a los movimientos de justicia ambiental. Como relata un informe al respecto, las empresas extractivistas en América Latina han incrementado el abuso judicial de figuras penales como sabotaje, terrorismo, rebelión y asociación ilícita, entre otras, contra defensores de derechos humanos y líderes sociales opuestos a las industrias mineras intensivas (IDL Justicia Viva, 2012).

Para tal conexión de ámbitos, casi de forma simultánea a la creación o modificación de los marcos jurídicos mineros (analizado en el segundo paralelismo), en América Latina se han adaptado los marcos legales para criminalizar las protestas sociales (OCMAL, 2011: p. 20). Así, en Bolivia se promulgó en 2013 la Ley 367 que penaliza hasta con ocho años de cárcel el "avasallamiento" de las concesiones mineras.

Otra de las acciones de disuasión ha sido el uso indiscriminado de las fuerzas públicas (policiales o militares) para sofocar los actos de protesta social. Un estudio demostró que en todos los países sudamericanos con pueblos indígenas se han registrado violaciones de derechos para imponer emprendimientos extractivistas (Gudynas, 2013b). A su vez, en un reporte de la organización internacional Global Witness ${ }^{31}$ se contabilizaron 1024 asesinatos de activistas medioambientales cometidos entre 2002 y 2014. De los ocho países donde se había cometido el $89 \%$ de estos homicidios (es decir, 913), se hallaban seis latinoamericanos: Brasil, Colombia, Honduras, México, Perú y Guatemala.

\footnotetext{
30 El ocmal elabora mapas de criminalización de la protesta social dividiéndola en cuatro tipos: amenazas, asesinato/atentado, judicialización, y uso de la fuerza. Al 20 de agosto de 2018, el mapa del ocmaL contabilizaba 251 casos. (Recuperado el 20 de agosto de 2018, de https://mapa.conflictosmineros.net/ ocmal_db-v2/).

31 Véase https://www.globalwitness.org/en/about-us/annual-reviews/
} 
Los datos de represión, violación a los derechos humanos y asesinatos vinculados al extractivismo de cada país son elocuentes. En Colombia, organizaciones de derechos humanos calculan que el extractivismo minero ha ocasionado 5195620 desplazados, cincuenta mil desaparecidos y ciento cincuenta mil casos de tortura (Daumas, 2013: p. 54). En Honduras, de 2012 a 2014 se asesinaron a 111 personas relacionadas con la defensa de sus recursos naturales. ${ }^{32}$ En Perú, de 2006 a 2012 se contabilizan 206 muertos por conflictos sociales relacionados con empresas extractivas (Villegas, 2014: p. 56).

Como puede advertirse, el auge del extractivismo minero, el arropamiento institucional y las tentativas de usurpación territorial han generado y propagado por América Latina disputas, movimientos sociales y acciones de protesta que suelen recibir como respuesta gubernamental actos de disuasión, muchos de estos violentos. Pero con todo, la emergencia de los movimientos socioambientales evidencia un núcleo de impugnación al extractivismo minero y a los procesos estructurales que lo han impulsado, el cual ha conllevado a la formulación de gramáticas y proyectos alternativos a la racionalidad neoliberal a lo largo de la región. Ambas vertientes remiten a dos ámbitos imperiosos en América Latina: el modelo primario-exportador y la democracia.

\section{Presunciones. El modelo primario-exportador y la democracia}

El caso de la mina Marlin en el departamento de San Marcos en Guatemala no es aislado. Más bien, como se ha sustentado en este artículo, forma parte de paralelismos que configuran un modelo general sobre el extractivismo minero en América Latina.

Aun cuando se reconoce que hay excepciones que cuestionan los paralelismos, ${ }^{33}$ y sin pretender postular un enfoque monolítico sobre el tema, el panorama general sería el siguiente: en la última década ha habido un auge del

32 Recuperado el 14 de mayo de 2016, de http://www.noalamina.org/latinoamerica/general/item/15415varios-paises-latinoamericanos-al-tope-de-la-negra-lista-de-luchadores-ambientales-asesinados

33 Son tres las excepciones a los paralelismos expuestos. En primer lugar, las tasas de ganancia económica que los países han obtenido de la megaminería, las cuales oscilan entre participaciones considerables: Chile, Perú, Ecuador y Bolivia, a porcentajes nimios: Brasil, Honduras y México (Almonte \& Sánchez, 2016). Una segunda excepción se relaciona con casos (particularmente en Chile y Colombia) donde el Poder Judicial se ha involucrado activamente en los conflictos mineros, produciendo la paralización de proyectos mineros por afectaciones ambientales, incumplimientos administrativos o por falta de consulta previa. Por último, una tercera excepción a los paralelismos expuestos son casos en los que se han prohibido actividades extractivas mineras, ya sea en una región indígena (la comarca Ngäbe-Buglé en Panamá) o en todo el país (la ley de la Asamblea Legislativa que prohíbe la minería a cielo abierto en Costa Rica y la moratoria de facto en El Salvador). 
extractivismo minero en América Latina originado por demandas de bienes primarios y aumentos en los precios, y que ha sido favorecido por un cúmulo de facilidades institucionales, las cuales implican los ámbitos normativos (adecuaciones legislativas), administrativos (simplificaciones en los trámites), tributarios (incentivos fiscales a las inversiones) y discursivos (estrategias narrativas de legitimación de la minería). Tal vez la característica más relevante del extractivismo minero contemporáneo es la de pretender la apropiación territorial, lo que implica un consumo desmedido de los recursos naturales e impactos perniciosos al medio ambiente y las sociedades locales. Por lo anterior, se han incrementado los conflictos provocando la constitución de dos bloques antagónicos: uno, en contra de los proyectos extractivos, se ha articulado de una pluralidad de integrantes, discursos y repertorios de protesta; el otro, constituido por empresas transnacionales y gobiernos nacionales, que favorece los proyectos extractivos y suele enfrentar a los opositores mediante estrategias discursivas, judiciales y policiacas.

Tal esquema general remite, cuando menos, a dos trasfondos temáticos, uno económico y otro político: el modelo primario-exportador y la democracia. En primer lugar, el extractivismo minero ha profundizado la matriz exportadora de materias primas de América Latina, pues los datos disponibles evidencian que la estructura productiva se mantiene concentrada en los sectores primarios. En una medición de las Bases de Datos y Publicaciones Estadísticas de la CEPal, se indica que en un periodo de doce años (de 1999 a 2012), los países que más aumentaron su dependencia fueron, en ese orden, Bolivia, Brasil, Colombia y Uruguay. A su vez, los países que exportan productos primarios por encima del 90\% son Venezuela (95.5\%), Bolivia (95.1\%), Ecuador (91.2\%) y Paraguay (91.2\%), (Villegas, 2014: p. 24). Esto se debe, en gran medida, al aumento de la importancia de los minerales, pues mientras que en 1970 los minerales metalíferos e industriales suponían el 10\% del total de los flujos materiales de Latinoamérica, en 2009 han alcanzado el 25\% (Martinez-Alier \& Walter, 2015: p. 87).

Los datos anteriores reflejan una geografía de la extracción de recursos naturales muy diferente a la del consumo: "se da una clara diferenciación entre los países del Sur y del Norte geopolítico, concentrándose los procesos extractivos en los primeros y los mayores índices de consumo en los segundos." (Machado, 2011: p. 170). A pesar de que América Latina es de los principales proveedores de minerales, solo consume entre el 3 y el $6 \%$ del total mundial (Machado, 2010: pp. 84-86).

Pero la megaminería también remite a un asunto político central: la democracia. Según lo analizado hasta ahora, el extractivismo minero en América Latina cuando no ha producido, ha profundizado desigualdades económicas, 
exclusiones sociales e injusticias ecológicas que han ahondado las asimetrías políticas por triplicado. Primero, porque su implantación ha sido escoltada de mecanismos plutocráticos, conductas leoninas, relaciones clientelares, tráfico de influencias y opacidad de información. Segundo, porque ha considerado como nociva la deliberación que se realice fuera de los términos y los objetivos establecidos por el propio extractivismo, resultando de ello la limitación, la reducción y hasta la clausura de los espacios y las formas de participación ciudadana. Y, tercero, porque cuando organizaciones y movimientos sociales han desarrollado sus repertorios de acción colectiva, entre los cuales han recreado prácticas participativas (consultas, audiencias públicas, referendos, etcétera), la respuesta común ha sido, en el mejor de los casos, el desdén o la ridiculización y, en el peor, la represión, el encarcelamiento y el asesinato. Ocurriendo así lo que puede ser la mayor perversión del Estado: la invocación del Estado de derecho para vulnerar los derechos humanos de sus ciudadanos.

El escenario del apoyo institucional a la minería y las respuestas gubernamentales a las protestas sociales suscitan un doble cuestionamiento a la democracia liberal: a la representación y a los fundamentos liberales. Esto es, primero, hacia quienes son elegidos por voto popular pero que, además de alinearse con el extractivismo, minimizan, ignoran o combaten las posturas de los ciudadanos movilizados, oponiéndose a las deliberaciones públicas y evitando la rendición de cuentas. Y, segundo, hacia la negación y/o limitación de los derechos, principios y mecanismos liberales y su uso discrecional para sostener al extractivismo minero.

Aunque a partir de 2012 los precios de los bienes primarios han descendido, se proyecta que China y otras regiones emergentes mantengan sus procesos económicos, por lo que se espera que persista la demanda mundial de los productos primarios durante la presente década (Almonte $\&$ Sánchez, 2016: p. 25). Así, se prevé que el extractivismo minero proseguirá en América Latina.

Se advierte, entonces, que continuarán las facilidades institucionales y los impactos de la apropiación territorial en América Latina. Y con toda certeza se mantendrán las prácticas y discursos provenientes de organizaciones y movimientos que, mientras interpelan al modelo extractivista, muestran signos de un poder constituyente que todavía palpita en la región. Ello demanda necesariamente el examen profuso del modelo económico y los sistemas políticos de la región.

Como lo aseveró doña Dominga Vázquez Julaju, exalcaldesa indígena de Sololá en Guatemala, cuando me narró sobre el conflicto con la mina Marlin: "nosotros los pueblos indígenas no somos una marca, somos lo que hacemos y queremos para existir. Y por eso no dejaremos de luchar, porque la minería nos trae destrucción y nosotros queremos vivir." 


\section{Referencias}

Agencia de Regulación y Control Minero. (2016). Rendición de cuentas 2016. Recuperado el 4 de octubre de 2017, de http://www.controlminero.gob.ec/

Alimonda, H. (Coord.). (2011). La naturaleza colonizada. Ecología política y minería en América Latina. Buenos Aires: CLACSO.

Almonte, H. \& Sánchez, R. (2016). Hacia una nueva gobernanza de los recursos naturales en América Latina y el Caribe. Santiago: CEPAL.

Anaya, J. (2011). Informe del Relator Especial de Naciones Unidas sobre los Derechos de los Pueblos Indigenas, James Anaya. Adición: Observaciones sobre la situación de los derechos de los pueblos indigenas de Guatemala en relación con los proyectos extractivos, y otro tipo de proyectos, en sus territorios tradicionales. Apéndice: la situación de los derechos humanos de las comunidades afectadas por la mina Marlín, en las municipalidades de San Miguel Ixtahuacán y Sipacapa, Departamento de San Marcos (Guatemala). Nueva York: onU.

Antonelli, M. (2009). Minería transnacional y dispositivos de intervención en la cultura. La gestión del paradigma hegemónico de la "minería responsable y el desarrollo sustentable". En M. Svampa \& M. Antonelli (Eds.), Minería transnacional, narrativas del desarrollo y resistencias sociales (pp. 51-102). Buenos Aires: Biblos.

Baca, E. \& Ávila, G. (2015). Al final de una década de boom, ¿qué le dejó la minería al Perú? Balance 2004-2014. Lima: Grupo Propuesta Ciudadana.

Bastos, S. \& De León, Q. (2015). Guatemala: construyendo el desarrollo propio en un neoliberalismo de posguerra. Revista Pueblos y Fronteras Digital, 10(19) 52-79. Recuperado el 17 de septiembre de 2015, de http://www.redalyc.org/articulo.oa?id=90638786004

Banco Interamericano de Desarrollo (BID). (2012). Aprovechando las oportunidades para un crecimiento sostenible. Plataforma de Biodiversidad del BID para América Latina y el Caribe. Recuperado el 25 de abril de 2015 de http://idbdocs.iadb.org/wsdocs/getDocument .aspx?DOCNUM=36938440

Campodónico, H. \& Ortiz, G. (2002). Características de la inversión y del mercado mundial de la minería a principios de la década de 2000. Santiago: CEPAL.

Carrere, R. (Coord.). (2004). Minería. Impactos sociales y ambientales. Montevideo: Movimiento Mundial por los Bosques Tropicales.

Castagnino, V. (2006). Mineria de metales y derechos humanos en Guatemala. La mina Marlin en San Marcos. Guatemala: Brigadas de Paz Internacionales. 
Comisión Económica para América Latina y el Caribe (CEPAL). (2014). Los pueblos indígenas en América Latina. Avances en el último decenio y retos para la garantía de sus derechos. Santiago: CEPAL.

Confederación Sindical de Trabajadores y Trabajadoras de las Américas (CSA), Confederación Sindical Internacional (CsI), Consejo de los Pueblos de Occidente (CPO) \& Movimiento Sindical, Indígena y Campesino Guatemalteco (MSICG). (2010). El derecho de consulta de los pueblos indígenas en Guatemala: la ruptura entre el discurso y la práctica. Guatemala: $\mathrm{CSA} / \mathrm{CSI} / \mathrm{CPO} / \mathrm{MSICG}$.

Daumas, L. (2013). Políticas mineras en Latinoamérica: grandes similitudes y diferencias aparentes. Petropress, (30), 52-56. Recuperado el 19 de mayo de 216, de http://www.cedib .org/wp-content/uploads/2013/01/Politicas-mineras-en-latinoamerica-grandes-similitudes -y-diferencias-aparentes.pdf

Delgado Ramos, G. (2013). Costos ecológicos de la minería aurífera a cielo abierto y resistencia social. Intersecciones en Antropología, 14(1), 279-294.

Delgado Ramos, G. (Coord.). (2010). Ecología política de la minería en América Latina. México: CEIICH, UNAM.

Estado Plurinacional de Bolivia. Servicio Geológico Minero. (2013). Contratos y solicitudes de arrendamiento minero existentes en el territorio nacional-gestión 2013. Recuperado el 30 de junio de 2016, de http://sergeomin.gob.bo/images/memoria2013/cartografia.html

Garay Zarraga, A. (2014). La minería transnacional en Centroamérica: lógicas regionales e impactos transfronterizos. El caso de la mina Cerro Blanco. Madrid: Paz con Dignidad.

Giarracca, N. \& Teubal, M. (2010). Disputas por los territorios y por los recursos naturales: el modelo extractivo. Revista ALASRU, (5, Nueva Época), 113-133.

Giraud, M. (2006). Aspectos ambientales y socioeconómicos de la actividad minera. Recuperado el 12 de enero de 2016, de https://exactasbienescomunes.files.wordpress.com/2012/03/ giraud.pdf

Gobierno de Chile. Ministerio de Minería. (2018). Anuario de la Minería de Chile 2017. Recuperado el 20 de agosto de 2018, de http://www.sernageomin.cl/anuario-de-la-mineria-de -chile/

Gobierno de la República de Guatemala. Ministerio de Energía y Minas. (s. f.). Derechos mineros otorgados por Depto. Recuperado el 4 de octubre de 2017, de http://www.mem.gob.gt /mineria/catastro-minero/derechos-mineros-otorgados-por-depto/ 
Gobierno de la República de Panamá. Ministerio de Comercio e Industrias. (2016a). Concesiones de minerales metálicos. Actualizado al 30 de mayo de 2016. Recuperado el 14 de junio de 2016, de http://www.mici.gob.pa/imagenes/pdf/contratos_metalicos_mayo_2016.pdf

Gobierno de la República de Panamá. Ministerio de Comercio e Industrias. (2016b). Contratos de minerales no metálicos. Actualizado al 30 de mayo de 2016. Recuperado el 14 de junio de 2016, de http://www.mici.gob.pa/imagenes/pdf/contratos_no_metalicos_mayo_2016.pdf

Gobierno de los Estados Unidos Mexicanos. Presidencia de la República. (2017). 5to Informe de Gobierno 2016-2017. Ciudad de México, agosto. Recuperado el 5 de octubre de 2017, de http://www.presidencia.gob.mx/quintoinforme/

González, S. (2015). Impactos ambientales y en la salud humana de la minería a cielo abierto para la extracción de oro utilizando lixiviación con soluciones de cianuro. Recuperado el 6 de diciembre de 2015, de http://www.bolsonweb.com.ar/diariobolson/detalle.php?id_noticia=25224

Gudynas, E. (2013a). Extracciones, extractivismos y extrahecciones. Observatorio del Desarrollo, (18). Recuperado el 20 de abril de 2015, de http://www.extractivismo.com/documentos/ GudynasApropiacionExtractivismoExtraheccionesOdeD2013.pdf

Gudynas, E. (2013b, 12 de junio). Derechos indígenas violados: otra cara de las extrahecciones. El Espectador. Embrollos del Desarrollo [Blog], Bogotá. Recuperado el 27 de mayo de 2016, de http://blogs.elespectador.com/embrollodeldesarrollo/2013/06/12/derechos -indigenas-extrahecciones/

Harvey, D. (2004). The New Imperialism: Accumulation by Dispossession. Socialist Register, 40, 63-87.

Hernández Morales, C. (2014). Minería y sobreexplotación de la naturaleza en América Latina: caracterización de la minería contemporánea a través del caso mexicano. Tesis de Maestría en Estudios Políticos y Sociales, Universidad Nacional Autónoma de México, México.

IDL Justicia Viva. (2012). Informe. La criminalización de las protestas sociales durante el primer año del gobierno de Ollanta Umala "De la gran transformación a la mano dura". Lima: IDL Justicia Viva.

Instituto Centroamericano de Estudios Fiscales (ICEFI). (2014). La minería en Guatemala: realidad y desafios frente a la democracia y el desarrollo. Guatemala: ICEFI.

Instituto Hondureño de Geología y Minas (INHGeomin). Unidad registro minero y catastral. (2017). Listado de concesiones otorgadas al 30 de junio del 2017. Recuperado el 5 de octubre de 2017, de http://portalunico.iaip.gob.hn/portal/index.php?portal=342 
La Iniciativa para los Derechos y los Recursos (RRI). (2013). Impacto de las industrias extractivas en los derechos colectivos sobre territories y bosques de los pueblos y comunidades. Bogotá. Recuperado el 3 de febrero de 2015, de http://www.rightsandresources.org/documents/files/ doc_5914.pdf

Leff, E. (2003). La ecología política en América Latina: un campo en construcción. Sociedade e Estado, 18(1/2), 125-145.

Lillo, J. (2015). Impactos de la mineria en el medio natural. Madrid: Universidad Rey Juan Carlos.

Machado Aráoz, H. (2011). El auge de la minería transnacional en América Latina. De la ecología política del neoliberalismo a la anatomía política del colonialismo. En H. Alimonda (Coord.), La naturaleza colonizada. Ecología politica y minería en América Latina (pp. 135179). Buenos Aires: Clacso.

Machado Aráoz, H. (2010). "El agua vale más que el oro”. Grito de resistencia decolonial contra los nuevos dispositivos expropiatorios. En G. Delgado Ramos (Coord.), Ecología política de la minería en América Latina (pp. 59-96). México: CEIICH, unAM.

Mander, J. (Ed.). (2007). Manifesto on Global Economic Transitions. Washington: The International Forum on Globalization/The Institute for Policy Studies/The Global Economic Transitions Project.

Martínez Espinoza, M. (2015). Reconocimiento sin implementación. Un balance sobre los derechos de los pueblos indígenas en América Latina. Revista Mexicana de Ciencias Políticas y Sociales, $L X(224$, Nueva Época), 247-274.

Martinez-Alier, J. \& Walter, M. (2015). Metabolismo social y conflictos extractivos. En F. de Castro, B. Hogenboom \& M. Baud (Coords.), Gobernanza ambiental en América Latina (pp. 73-104). Buenos Aires: Clacso/Engov.

Martinez-Alier, J. \& O'Connor, M. (1996). Ecological and Economic Distribution Conflicts. En R. Costanza, O. Segura \& J. Martinez-Alier (Eds.), Getting down the Earth: Practical Applications of Ecological Economics (pp. 277-286). Washington: Island Press.

Ministerio de Energía y Minas (мем). (2004). Caracterización de la minería en Guatemala. Guatemala: Ministerio de Energía y Minas. Dirección General de Minería.

Ministerio de Energía y Minas. (2014). Anuario Estadístico Minero Colombiano 2007-2012. Recuperado el 14 de junio de 2016, de https://www.minminas.gov.co/anuario-estadistico-minero

Ministerio de Energía y Minas. Dirección General de Minas. Dirección de administración y control de concesiones. (2017). Estadisticas catastrales mineras. Recuperado el 5 de 
octubre de 2017, de www.mem.gob.ni/wp-content/uploads/2017/09/ESTADISTICAS -CATASTRALES-MINERAS-020817.pdf

Ministerio de Energía y Minas. Instituto Geológico, Minero y Metalúrgico. (2017). Ubicación de los derechos mineros por Departamento a nivel nacional. Recuperado el 5 de octubre de 2017, de http://ecatastro.ingemmet.gob.pe:83/PresentacionDatos/Reportes_Estadisticas.aspx

Ministerio de Energía y Minería de Argentina. (2016). Minería Argentina: lo mejor está por venir. Recuperado el 14 de junio de 2016, de http://pdac2016.minem.gob.ar/presentacion -argentina-pdac-2016-es.pdf

Ministério das Minas e Energia (MME). (2011). Plano nacional De Mineração 2030. Recuperado el 30 de junio de 2016, de http://www.mme.gov.br/documents/1138775/1732821/ Book_PNM_2030_2.pdf/f7cc76c1-2d3b-4490-9d45-d725801c3522

Morán, R. (2013). Preguntas y respuestas sobre minería. Buenos Aires: Greenpeace.

Nolasco, S. (2011). Impactos de la minería metálica en Centroamérica. San Salvador: CEICOM/OCMAL.

Observatorio de Conflictos Mineros de América Latina (ocmaL). (2015). Conflictos mineros en América Latina: extracción, saqueo y agresión. Estado de situación en 2014. Recuperado el 15 de mayo de 2015, de http://www.cpalsocial.org/documentos/185.pdf

Observatorio de Conflictos Mineros de América Latina (OCMAL). (2012). Legislación minera en el Derecho comparado. Los casos de: Chile, Ecuador, Perú, Guatemala. El Salvador: ocmal/ Broederlijk Denle/Misereor/Fedepaz.

Observatorio de Conflictos Mineros de América Latina (ocmal). (2011). Cuando tiemblan los derechos: extractivismo y criminalización en América Latina. Recuperado el 28 de enero de 2014, de http://www.conflictosmineros.net/agregar-documento/publicaciones-ocmal/cuando -tiemblan-los-derechos-extractivismo-y-criminalizacion-en-america-latina/detail

Oficina Regional para América Central del Alto Comisionado de las Naciones Unidas para los Derechos Humanos (oracacnudh). (2012). Diagnóstico sobre la situación de los derechos humanos de los pueblos indígenas en América Central. Tomo I. Panamá: ORACACNudH/Embajada de Noruega.

On Common Ground Consultants Inc. (OCGCI). (2010). Evaluación de los Derechos Humanos de la Mina Marlin de Goldcorp. Vancouver: OCGCI.

Rodríguez-Piñero, L. (2007). La internacionalización de los derechos indígenas en América Latina: ¿el fin de un ciclo? En S. Martí I Puig (Ed.), Pueblos indígenas y política en América 
Latina. El reconocimiento de sus derechos y el impacto de sus demandas a inicios del siglo XXI (pp. 181-200). Barcelona: Fundació сіDOB.

Sack, R. (1986). Human Territoriality: Its Theory and History. Cambridge: University Press.

Sánchez-Albavera, F. \& Lardé, J. (2006). Minería y competitividad internacional en América Latina. Santiago: CEPAL.

Sariego, J., Reygadas, L., Gómez, M. \& Farrera, J. (1988). El Estado y la minería Mexicana: política, trabajo y sociedad durante el siglo XX. México: FCE.

Saúl, L. (2015). Minas en México. El Universal. Recuperado el 5 de mayo de 2015, de http:// archivo.eluniversal.com.mx/graficos/graficosanimados14/EU_Mineria_Mexico/

Seoane, J. (2013a). Modelo extractivo y acumulación por despojo. En J. Seoane, E. Taddei \& C. Algranati, Extractivismo, despojo y crisis climática. Desafios para los movimientos sociales y los proyectos emancipatorios (pp. 21-39). Buenos Aires: Ediciones Herramienta/El Colectivo/ GEAL.

Seoane, J. (2013b). Estrategias de gobernabilidad del modelo extractivo exportador. En J. Seoane, E. Taddei \& C. Algranati, Extractivismo, despojo y crisis climática. Desafios para los movimientos sociales y los proyectos emancipatorios (pp. 239-255). Buenos Aires: Ediciones Herramienta/El Colectivo/GEAL.

Seoane, J., Taddei, E. \& Algranati, C. (2013). Extractivismo, despojo y crisis climática. Desafios para los movimientos sociales y los proyectos emancipatorios. Buenos Aires: Ediciones Herramienta/ El Colectivo/GEAL. Recuperado el 10 de enero de 2017, de http://www.iheal.univ-paris3.fr/ sites/www.iheal.univ-paris3.fr/files/SEOANE-TADDEI-ALGRANATI\%202013.pdf

Svampa, M. (2012, noviembre). Consenso de los commodities, giro ecoterritorial y pensamiento crítico en América Latina. OSAL, XIII(32), 15-38.

Svampa, M. (2008). La disputa por el desarrollo: territorio, movimientos de carácter socio-ambientaly discursos dominantes. Recuperado el 20 de agosto de 2018, de http://www.maristellasvampa .net/archivos/ensayo43.pdf

Tarrow, S. (2004). El poder en movimiento. Los movimientos sociales, la acción colectiva y la política. Madrid: Alianza.

United Nations Development Programme (UNDP). (2010). Latin America and the Caribbean. A biodiversity super power. Recuperado el 2 de marzo de 2015, de http://www.undp.org/ content/dam/undp/library/Environment $\% 20$ and\%20Energy/biodiversity/Latin-America -and-the-Caribbean---A-Biodiversity-Superpower--Policy_Brief_ENG.pdf 
United Nations Development Programme (UNDP). (2009). From Conflict to Peacebuilding: The Role of Natural Resources and the Environment. Nueva York: United Nations.

Urkidi, L. \& Walter, M. (2011). Dimensions of Environmental Justice in anti-gold mining movements in Latin-America. Geoforum, (42), 683-695. Recuperado el 14 de agosto de 2015, de https://www.researchgate.net/profile/Mariana_Walter/publication/241127080_ Dimensions_of_Environmental_Justice_in_Anti-Mining_Movements_in_Latin_ America/links/543d1e0b0cf2c432f7424f57.pdf

Villafuerte Solís, D. (2014, septiembre-diciembre). Neoextractivismo, megaproyectos y conflictividad en Guatemala y Nicaragua. Espiral, XXI(61), 109-141.

Villegas, P. (2014). Amistades peligrosas: notas sobre movimientos sociales y gobiernos progresistas. En M. Gandarillas Gonzáles (Ed.), Extractivismo: nuevos contextos de dominación y resistencia (pp. 9-66). Bolivia: CEDIB.

Walter, Mariana \& Urkidi, L. (2015). Consultas comunitarias. Respuestas a la minería a gran escala en América Latina. En F. de Castro, B. Hogenboom \& M. Baud (Coords.), Gobernanza ambiental en América Latina (pp. 331-370). Buenos Aires: CLACSO/Engov.

WwF International \& Terralingua. (2000). Indigenous and Traditional Peoples of the World and Ecoregion Conservation: An Integrated Approach to Conserving the World's Biological and Cultural Diversity. Suiza: WwF International/Terralingua.

Yagenova, S. (Coord.). (2012). La industria extractiva en Guatemala: Politicas públicas, derechos humanos, y procesos de resistencia popular en el periodo 2003-2011. Guatemala: Flacso Guatemala.

Zarsky, L. \& Stanley, L. (2011). Buscando oro en el altiplano de Guatemala: beneficios económicos y riesgos ambientales de la mina Marlin. Medford: Instituto de Desarrollo Global y Medio Ambiente. 